\title{
Recurrent Malignant Head and Neck Neoplasm
}

National Cancer Institute

\section{Source}

National Cancer Institute. Recurrent Malignant Head and Neck Neoplasm. NCI

Thesaurus. Code C152077.

The reemergence of a malignant head and neck neoplasm after a period of remission. 